\title{
The Distance Ecological Model to Support Self/Collaborative-Learning in the Internet Environment
}

\section{T. Okamoto}

University of Electro-Communications, Graduate School of Information Systems, 1-5-1 Chofugaoka Chofu-shi Tokyo, 182-8585 Japan

Keywords: Distance Education, Teacher Training System, Distance Educational Model, Learning Ecology, School Based Curriculum Development, Training System

Abstract: With the rapid development of information technology, computer and information communication literacy has become extremely important. As a result, teachers require new skills. A new teachers' education framework is necessary to enhance multimedia teaching skills and information literacy about the Internet environment. The purpose of this study is to propose and develop a Distance Educational Model, which is a School-Based Curriculum Development and Training-System (SCOUTS). In this environment, a teacher can learn subject contents, teaching knowledge, and evaluation methods of students' learning activities, related to the new subject called "Information", via an Internet based self-training system. In this paper, we describe the structure, function and mechanism of the Distance Educational Model, and then describe the educational meaning of this model in consideration of the new learning ecology, which is based on multi-modality and new learning situations and forms.

\section{INTRODUCTION}

Recently, with the development of information and communication technologies, various teaching methods using Internet, multimedia, and so on, are being introduced. Most of these methods emphasise, in particular, the aspect of collaborative communication between students and teacher during interactive teaching and learning activities. Therefore, now-a-days it is 
extremely important for a teacher to acquire computer communication literacy (Nishinosono, 1998).

So far, there have been many studies concerning system development, which aim at fostering and expanding teachers' practical abilities and comprehensive teaching skills by using new technologies, such as computers, Internet, multimedia, and so on. In Japan, systems using communication satellites such as SCS (Space Collaboration System) are developed and used as distance education systems between Japanese national universities. In the near future, a teacher's role will change from text based teaching to facilitating, advising, and consulting. His or her role will be more that of a designer of the learning environment. Therefore, a teacher has to constantly acquire new knowledge and methodologies. We have to build a free and flexible self-teaching environment for them under the concept of "continuous education". At the same time, we need to build a collaborative communication environment to support mutual deep and effective understanding among teachers.

In this paper, we propose a Distance Educational Model, which is based on the concept of School Based Curriculum Development and Training System, advocated by UNESCO and OECD/CERI (Center for Educational Research and Innovation). We describe the structure, function, mechanism and, finally, the educational meaning of this model. It is necessary to construct an individual, as well as a collaborative, learning environment that supports teachers' self-learning and training, by using Internet distributed environments and multimedia technologies. A teacher can choose the most convenient learning media to learn the contents (subject units) that $\mathrm{s} / \mathrm{he}$ desires.

\section{DISTANCE EDUCATIONAL MODEL BASED ON SCOUTS}

Until now, when a teacher wanted to take a class on "IT-education", s/he had usually to leave the classroom or school. However, it is now possible to learn various kinds of subject contents by building a virtual school on the Internet environment.

\subsection{Distance Educational Model}

Our Distance Educational Model is built on three dimensions. The first one is subject-contents, which represents what the teachers want to learn. The second one represents teaching knowledge and skills as well as evaluation methods of students' learning activities. From the third axis, a favourite 
learning media (form) can be chosen, e.g. VOD, CBR, etc. By selecting a position on each of the three axes, a certain cell is determined. A cell stands for a "script", which describes the instruction guidelines of the learning contents, the self-learning procedure, and so on. Figure 1 shows the structure of this model. A more detailed explanation of each axis follows.

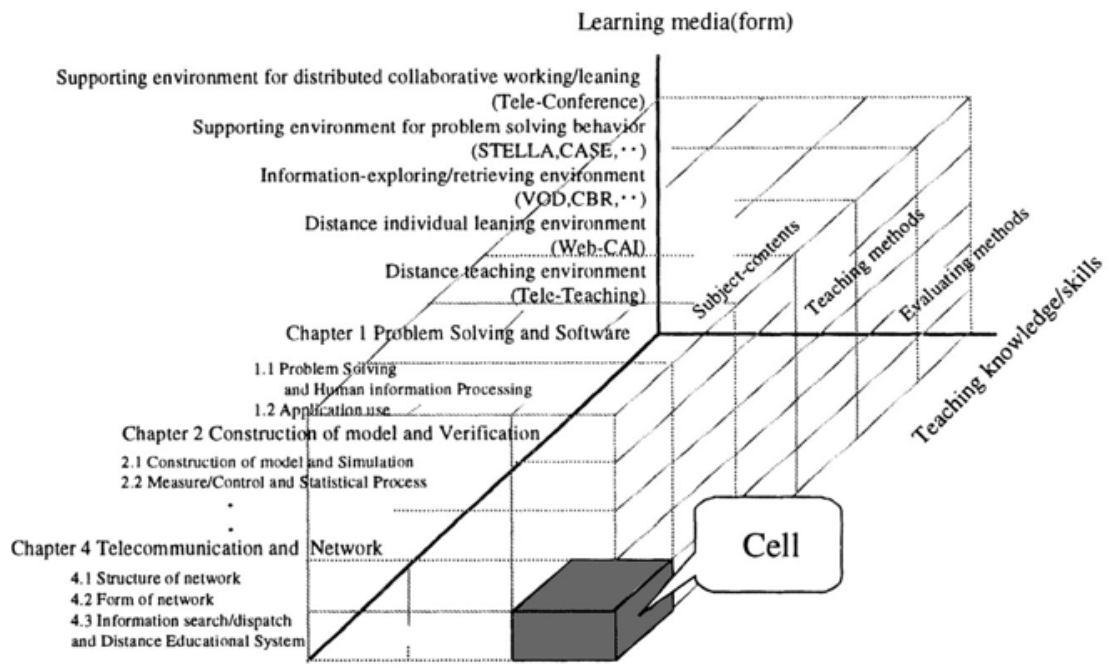

Subject-contents unit (About Information B)

Figure 1. Structure of the Distance Educational Model

\subsubsection{Subject-contents unit}

In this study, we focus on the subject "Information", which is due to be established as a new obligatory subject in the regular courses of the academic high school system in Japan. The subject "Information" is composed of three sub-subjects, "Information A", "Information B" and "InformationC". The contents of each sub-subject are as follows.

Information $A$ : This sub-subject places importance on raising the fundamental skills and abilities to collect, process and transmit "information" using computers, the Internet and multimedia.

Information B: This sub-subject places importance on understanding the fundamental scientific aspects and the practical usage methods of "information".

Information C: This sub-subject places importance on fostering desirable and sound behaviour regarding participation, involvement and contribution in an information society. It focuses on understanding 
people's roles and the influence and impact of technology in the new information society.

\subsubsection{Teaching knowledge/skills}

On this dimension, we have represented three items, which are: sub-subject contents, teaching methods and evaluating methods for "information" classroom teaching. The item 'teaching methods' stands for how to use and apply IT, in order to enhance a student's problem solving ability. This involves comprehensive learning activities, such as problem recognition, investigation and analysis, planning and design, implementation and execution, evaluation, report and presentation. We aim at teachers acquiring the proper respective evaluation skills of students' achievements, for each of the above activities.

\subsubsection{Learning media(form)}

This dimension represents five different learning environments: (1) "Distance teaching environment (Tele-Teaching)", based on one-to-multisites telecommunications; (2) "Distance individual learning environment (Web-CAI)", based on CAI (Computer Assisted Instruction) using World Wide Web facilities; (3) "Information-exploring and retrieving environment", using VOD (Video on Demand) or CBR (Case Based Reasoning); (4) "Supporting environment for problem solving", by providing various effective learning tools; and (5) "Supporting environment for distributed collaborative working/learning", based on multi-multi-sites telecommunications. Brief explanations for each environment follow.

1. Distance teaching environment (Tele-Teaching): This environment delivers the instructor's lecture image and voice information through the Internet, by using the real-time information dispatching function via VOD(Video On Demand).

2. Distance individual learning environment (Web-CAI): This environment provides CAI (Computer Assisted Instruction) courseware with World Wide Web facilities on the Internet.

3. Information-exploring and retrieving environment: This environment delivers, according to the teacher's demand, the instructor's lecture image and voice information, which was previously stored on the VOD server. For delivery, the function 'dispatching information accumulated on the VOD server' is used. In addition, this environment provides a CBR system with short movies about classroom teaching practices. 
4. Supporting environment for problem solving: This environment provides a tool library for performance support based on CAD Modelling tools, Spreadsheets, Authoring tools, and so on.

5. Supporting environment for distributed collaborative working and learning: This environment provides a groupware with a shared memory window, using text, voice and image information for trainees.

\section{2 "Cell" definition}

The concept of a "cell" in the Distance Educational Model is quite important because it generates the training scenario, including information to satisfy the teacher's needs, the subject materials learning-flow and the guidelines for self-learning navigation. The frame representation of the "cell" is shown in Table 1. These slots are used when the system guides the process of the teacher' s self- learning.

Table 1. The frame representation of the "cell"

\begin{tabular}{|l|l|l|}
\hline \multicolumn{2}{|l|}{ Frame-name: } & \multicolumn{1}{l|}{ Slot-Value } \\
\cline { 3 - 3 } & Learning objectives for astudent & $\begin{array}{l}\text { Subjects which should be understood } \\
\text { Subjects which should be mastered }\end{array}$ \\
\hline Subject-contents & The unit topic \\
\hline Teaching method & $\begin{array}{l}\text { The students' supervision method and } \\
\text { instructional strategies }\end{array}$ \\
\hline Evaluating method & The students' evaluation method \\
\hline Useful tools & The software used for the training actvity \\
\hline Operational manual of tools & $\begin{array}{l}\text { The software operation method used for the } \\
\text { training actvity }\end{array}$ \\
\hline Prepared media & The learning media which can be selected \\
\hline Guide script & $\begin{array}{l}\text { The file which specifies the dialog between the } \\
\text { trainee and the system }\end{array}$ \\
\hline
\end{tabular}

\section{OUTLINE OF THE TEACHER TRAINING SYSTEM}

The system configuration of the teacher's training environment is composed of two subsystems based on the Distance Educational Model. One of the subsystems is the training system, where a trainee can select and learn the subject s/he needs, guided by the script in the "cell". The other subsystem is an authoring system with creating and editing functions for "cell" description. The users of the second environment are, for example, IT- 
coordinators or IT-consultants, who can design lecture-plans in this environment.

\subsection{Training system}

The training system aims to support teachers' self-training. The configuration of this system is shown in Figure 2. The role of this system is first to identify a "cell" in the model, according to the teachers' needs. Then, the system tries to set up an effective learning environment, by retrieving the proper materials for the teacher, along with the "guide script" defined in the corresponding "cell". Therefore, the system offers programs for both Retrieving and Interpreting. The training system works thus:

STEP 1: Record the teacher's needs.

STEP 2: Select a "cell" in the Distance Education Model according to the teacher's needs.

STEP 3: Interpret the "cell" in the guide WM (Working Memory).

STEP 4: Develop the interactive training with the teacher according to the "guide script" in the guide WM.

STEP 5: Store the log-data of the dialog. The log-data collects information on the learning histories and teachers' needs and behaviours. STEP 6: Provide the necessary and useful applications for the user's learning activities and set up an effective training environment.

STEP 7: Give guidance-information, according to the "cell" script guidelines, and decide on the proper "cell" for the next learning step.

Here, it is necessary to explain the dialog mechanism (algorithm) between user and system. The interpreter controls and develops the dialog process between user and machine according to the information defined in our "guide script" description language. This "guide script" description language (GSDL) consists of some tags and a simple grammar for interpreting a document, similar to the HTML (Hypertext Mark-up Language) on the World WideWeb. 


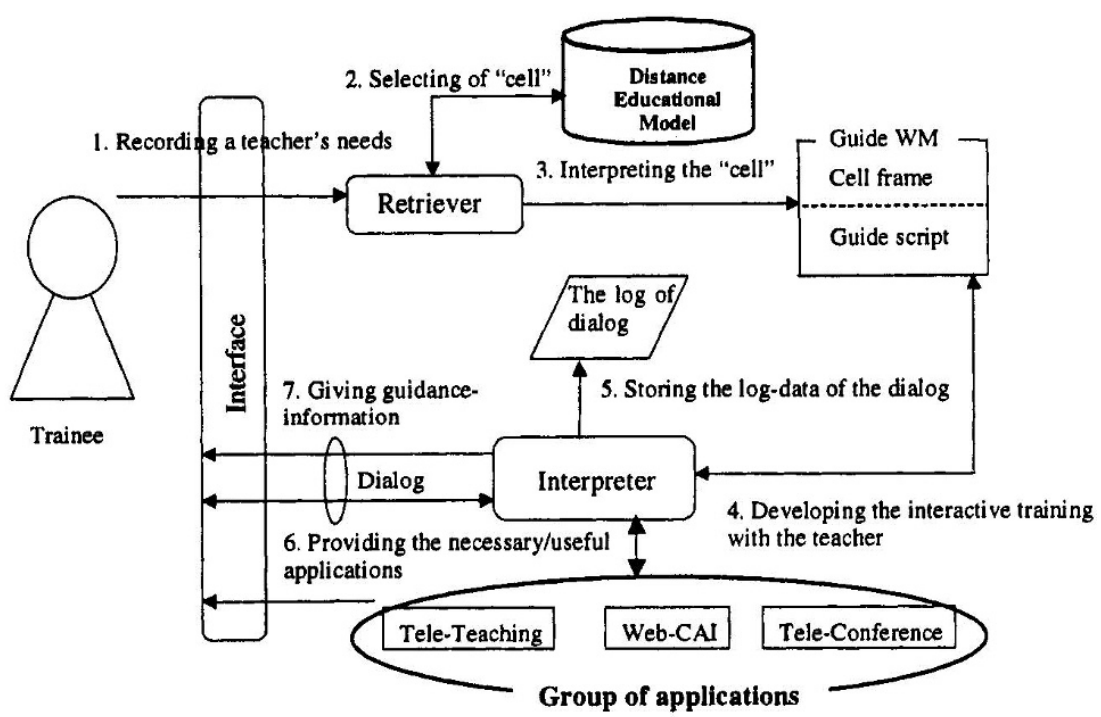

Figure 2. Configuration of training system

The interpreter understands the meanings of the tags, and interprets the contents. An example of GSDL is shown below.

1. $<$ free $>$ Definition: description of the text (instruction)

2. <slot (num.) > Definition: a link to a slot value in the "cell"

3. <question> Definition: questions to a trainee

4. <choice > Definition: branching control according to a trainee's response

5. <exe> Call: to relevant "cells"

6. $<$ app $>$ Definition: applications used for training activities (e.g. TeleTeaching, etc.)

\subsection{Authoring system for creating and editing a "cell" description}

The system provides an authoring module to create and edit the information in the "cell". This module also offers the function of adding new "cells", in order to allow supervisors (experienced teachers) to design the teachers' training program. The configuration of this system is shown in Figure 3. The tasks that can be performed by this system are: adding new "cells", editing the existing "cells", receiving calls for Tele-Teaching lectures, and managing the lectures schedule. This system is composed of the "cell" frame creating module, and the "guide script" creating module. A cell design can be performed as shown in the following. 
STEP 1: Get the slot-values of "student's learning objectives", "subjectcontents/teaching method/evaluating method", and "useful tools" from the "cell".

STEP 2: Substitute the return value of the slot of the prepared media with the training-contents corresponding to the user's needs.

STEP 3: Substitute the slot-value in the "cell" for the corresponding tag in the "guide script" template.

STEP 4: If "Tele-Teaching" as learning media is selected, then get some information about the lecture, by referring the lecture-DB and the VOD short movie-DB.

STEP 5: Add the new "cell” to the Distance Educational Model.

The lecture-database consists of "lesson managing files" containing userprofile data, lecture schedules, trainees' learning records, lecture abstracts, and so on. The "guide script" template file contains tag-information, written in the "guide script" description language (GSDL), for all subject-contents items in the Distance Educational Model.

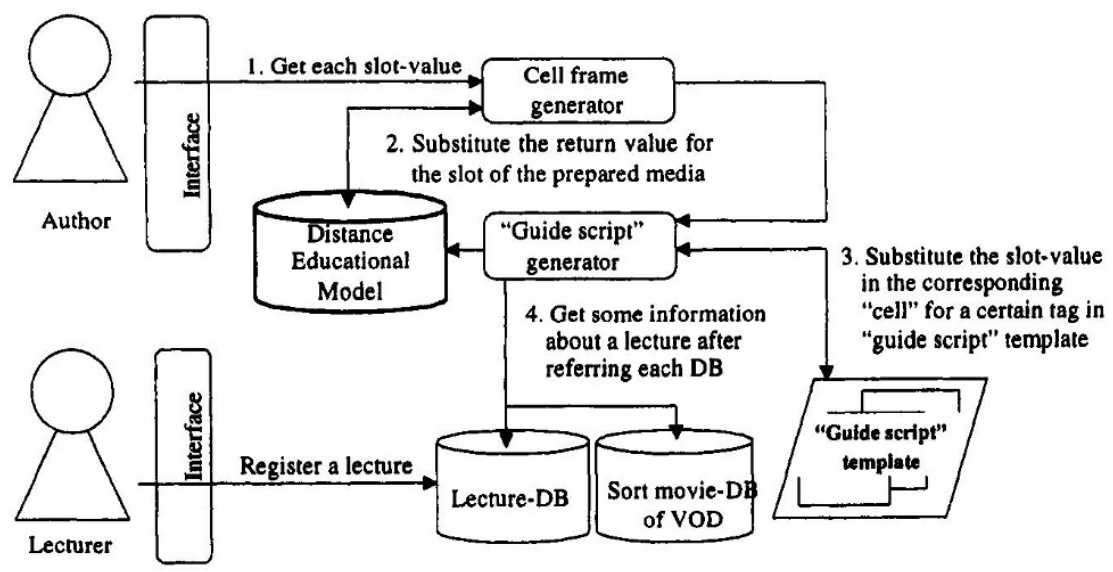

Figure 3. The procedure of "cell" description for creating/editing the authoring system

\section{CONCLUSION}

This paper proposed the Distance Educational Model called the "School Based Curriculum Development and Training System" (SCOUTS). This model stands for the networked virtual leaning environment based on a three dimensional representation, which has on the axes, (1) subject-contents, e.g. 
"information" for the training, (2) teaching knowledge, skills and evaluation methods, and (3) learning and teaching media (forms). This represents a new framework for teachers' education in the coming networked age. We have mentioned the rationale of our system and explained the architecture of the training system via a 3D-representation model. Furthermore, we have described a "guide script" language. The aim of our system is to support teachers' self-learning, provided as in-service training. At the same time, we need to build rich databases by accumulating various kinds of teaching expertise. In such a way, the concept of "knowledge-sharing" and "knowledge-reusing" will be implemented. As a result, we trust that a new learning ecology scheme will emerge from our environment.

With this system, we can construct various kinds of learning forms and design interactive and collaborative activities among learners. Such an interactive learning environment can provide a modality of externalised knowledge-acquisition and knowledge-sharing, via the communication process, and support learning methods such as "Learning by asking", "Learning by showing", "Learning by Observing, "Learning by Exploring", and "Learning by Teaching/Explaining". Along with the learning effects expected from this system, we also aim at meta-cognition and distributed cognition, such as reflective thinking, self-monitoring, and so on. Therefore, we expect to build a new learning ecology, as mentioned above, through this system. Finally, we will apply this system to the real world and try to evaluate its effectiveness and usability from an experimental and practical point of view.

\section{REFERENCES}

Collis, B. (1999). Design, development and implementation of a WWW-based course-support system. Proceedings of ICCE99, IOS Press.

Nishinosono, H. (1998). A teacher education system for information education teachers at high school level in the information society. Proceedings of the Conference JET. Salvador, L.G. (1999). Continuing education through distance training. Proceedings of ICCE99, IOSPress.

Seki, K., Takaoka, R., Matsui, T., \& Okamoto, T. (1998). A teaching model in distance education based on teacher's needs. IEICE Technical Report, ET98-12.

UNESCO. (1998). World declaration on higher education for the twenty-first century: Vision and action. Paris: UNESCO. 